\title{
O FANTÁSTICO: PROCEDIMENTOS DE CONSTRUÇÃO NARRATIVA EM H.P. LOVECRAFT. FILIPE FURTADO. 2017
}

Renata Philippov (USP)

Recebido em 28 fev 2018. Renata Philippov é Doutora em Letras (USP) e Aprovado em 31 mai 2018. Pós-Doutora em Linguística Aplicada (PUC/SP). É Professora Associada da UNIFESP, campus Guarulhos. Atua na área de Língua Inglesa e Literaturas de Língua Inglesa e no Programa de Mestrado em Letras nessa instituição. É autora de artigos e capítulos de livros nacionais e internacionais, bem como coorganizadora do livro Desencapsulando Currículos do Ensino Superior (PONTES, 2015). É líder do GP Língua e Literatura: interdisciplinaridade e docência e pesquisadora dos GPs Vertentes do Fantástico e Linguagem e Aprendizagem em Contexto Escolar. Também é membro do GT Vertentes do Insólito Ficcional (ANPOLL). Tem interesse em insólito ficcional, dedicando-se principalmente à pesquisa sobre obras de Edgar Allan Poe, Charles Baudelaire e Machado de Assis. Lattes: http://lattes.cnpq. br/9950264048329182. E-mail: renata.philippov@ unifesp.br 
Publicado em 2017 pela Editora Dialogarts (Universidade do Estado do Rio de Janeiro - UERJ), com edição dos Professores Flavio García e Júlio França, ambos dessa mesma universidade, o até então inédito e desconhecido 0 Fantástico: procedimentos de construção narrativa em H.P.Lovecraft, de Filipe Furtado, foi uma grata surpresa para seus editores e para os especialistas no gênero

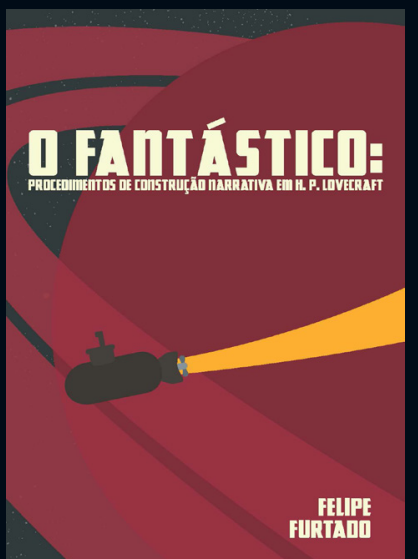
e na obra do escritor norte-americano. Trata-se da segunda parte da tese de mestrado de Furtado, intitulada A construção do fantástico em H.P.Lovecraft, composta de dois volumes e defendida em 1979, na Faculdade de Letras da Universidade de Lisboa. A primeira parte veio a público sob o título $A$ construção do fantástico na narrativa (Lisboa: Livros Horizonte, 1980), obra que hoje encontra-se esgotada e praticamente inacessível. No entanto, diz-nos Flavio García, na apresentação deste segundo volume da tese de Filipe Furtado, que já está sob contrato com a Editora Dialogarts a publicação em solo brasileiro desse primeiro volume, há tanto esgotado. Seu breve lançamento será fundamental para os estudiosos do fantástico, já que a obra é central nos estudos do gênero em língua portuguesa.

Esta segunda parte retoma do ponto onde parou a primeira: um estudo minucioso, sob o prisma estruturalista, de contos fantásticos de horror de Lovecraft, autor muito apreciado por leitores brasileiros, mas pouco estudado e carente de estudos de fôlego como este volume se propõe a percorrer. O livro é precedido de dois textos de apresentação, sendo um primeiro 
de autoria de Flavio García e um outro, de Júlio França. García esclarece ao leitor todo o processo de descoberta surpreendente da obra, como dito acima, até então inédita e desconhecida por todos. Em 2015, durante cafés informais em que Furtado e o professor da UERJ se encontraram para discutir a publicação da tese de doutorado de Furtado, igualmente inédita e atualmente em processo de publicação pela Dialogarts, García descreve o momento surpreendente em que Furtado presenteou-Ihe com um volume datilografado e com vários trechos comentados à mão e que pertencia à tese de mestrado do pesquisador português, mas da qual, naquele momento, ninguém conhecia a existência. Furtado havia guardado esse texto desde 1979 sob sigilo, na esperança de um dia publicá-lo. Após trâmites de cessão de direitos autorais e registros de acordo contratual, também relatados no texto de García, passou-se à edição, seleção, atualização e publicação do livro, processo sempre acompanhado de perto por Furtado. Esse longo processo é descrito por França no segundo texto que serve de apresentação ao livro. Nele, o leitor fica sabendo que os editores optaram por ajustes do manuscrito para que pudesse ser publicado em formato de livro. Uma das mudanças mais significativas foi a troca das longas citações originais retiradas das obras de Lovecraft, que no manuscrito apareciam em língua inglesa, por traduções retiradas de edições em língua portuguesa, de forma a que o leitor possa ter acesso mais fácil ao texto analisado. Por outro lado, os editores mantiveram todas as citações de textos teórico-críticos elencadas por Furtado em seu original. França justifica a escolha de tal procedimento pelo fato de os editores acreditarem que o leitor mais especializado poderá identificar tais textos e, se quiser, buscar 
eventuais traduções disponíveis em língua portuguesa ou, então, lê-los no original.

Na sequência, logo após essas duas apresentações, o livro traz uma breve introdução à obra de Filipe Furtado, intitulada "Filipe Furtado - um arquiteto do fantástico", de autoria do Professor Alexander Meireles da Silva (Universidade Federal de Goiás - UFG). Como o título já anuncia, em um texto breve, Silva traça a trajetória crítica de Furtado, mostrando como o pesquisador português teceu a arquitetura do gênero em outros estudos seus, principalmente no já bastante conhecido $A$ construção do fantástico na narrativa. Embora Silva não deixe isso claro no texto, o intuito parece ser o de localizar o leitor dentro da pesquisa de Furtado, retomando o ponto de partida do estudo e, assim, facilitando ao leitor o entendimento da perspectiva adotada por Furtado para essa segunda parte de seu trabalho sobre Lovecraft.

Ainda à guisa de apresentações ou introduções ao texto de Furtado, o livro traz o ensaio "H.P.Lovecraft - weird fiction for weird times: os tempos e paradoxos", de autoria do Professor Claudio Zanini (Universidade Federal de Ciências da Saúde de Porto Alegre - UFCSPA). Apesar de conciso, esse ensaio apresenta a obra de Lovecraft, preparando o leitor para um melhor entendimento do estudo de Furtado. O texto apresenta os aspectos mais relevantes da vida e obra do escritor norte-americano, seus paradoxos, seu diálogo com o contexto de produção de suas obras. Revela um autor denso, contundente, de difícil apreensão, por vezes tido como muito além de seu tempo e, portanto, incompreendido e relegado a segundo plano por muito tempo. Apoiando-se em alguns dos teóricos e estudiosos lovecraftianos mais recentes e importantes, Zanini localiza 
o leitor brasileiro dentro do paradigma temático com o qual o autor norte-americano lidou. Ao final do ensaio, o leitor tem acesso à bibliografia consultada pelo autor, o que ajuda a buscar outras fontes bibliográficas, em sua maioria não traduzidas para o português.

Tem-se, então, início da obra de Furtado, dividida em onze partes, sendo a última composta de referências bibliográficas - não se deve esquecer que estamos diante da publicação da segunda parte da tese de dissertação de mestrado do autor e uma estrutura assim faz parte do gênero. Cada capítulo vai fornecendo ao leitor o passo a passo de uma leitura atenta, focada nos procedimentos narrativos que Lovecraft utilizou, segundo Furtado, para criar o efeito de fantástico em seus contos. Como afirma França no texto acima mencionado, Furtado trabalha com um paradigma estruturalista, centrado no texto, paradigma esse que hoje pode parecer anacrônico, mas que, em 1979, ainda imperava fortemente na academia. Logo no primeiro parágrafo da primeira parte do texto, diz-nos Furtado qual é seu ponto de partida e qual recorte de corpus e análise utilizará no seu estudo:

O presente estudo é dedicado ao exame dos procedimentos de construção narrativa empregados por H. P. Lovecraft visando realizar os traços fundamentais do fantástico. Desse modo, apenas interessarão, ao que aqui se vai desenvolver, os textos do autor que evidenciem, em elevado grau, a totalidade ou, pelo menos, a maioria das características detectadas no gênero. $(2017$, p.43)

Percebe-se, logo de saída, uma preocupação com categorização, com taxonomia, preocupação que também aparece fortemente 
na obra publicada em 1980. Visando a se manter atrelado a um estudo sobre procedimentos narrativos dentro do fantástico na obra lovecraftiana, Furtado passa, então, a definir quais obras excluirá como corpus: "Polaris" (1918), dado seu "pendor para o maravilhoso" (p.43), "Nas muralhas de Eryx", por considerá-la "precursora da moderna ficção científica" (p.44), e as obras de Lovecraft em parceria com August Derleth. No mais, Furtado recorre ao conjunto de contos do autor norte-americano como forma de encontrar temas e motivos em comum. Chega, ainda na primeira parte de seu estudo, intitulada "Os temas centrais", a uma fórmula matemática: "avidez intelectual $\rightarrow$ possessão $\rightarrow$ destruição" (p.45). Ao longo desse capítulo, vai elencando uma série de contos em que o narrador, a personagem principal ou até mesmo uma comunidade inteira demonstram um fascínio incontrolável pelo saber científico, por conhecer, para além da realidade objetiva, algo que, muitas vezes, pertence a um passado intangível e mítico. Tal fascínio, que Furtado chama de avidez intelectual, leva, em todos os contos por ele elencados e analisados, à possessão de algo demoníaco e incontrolável que, por sua vez, levará personagens e comunidades inteiras à destruição inexorável. É assim em "Um sussurro das trevas", "Um assombro das trevas", "A tumba" e "O chamado de Cthulhu", por exemplo. Arqueólogos, cientistas tomados pela ânsia de conhecer, assistentes de pesquisa, comunidades científicas estão fadados a tal fórmula matemática inexorável, segundo a leitura de Furtado, que esmiúça detalhes das descrições de sensações sofridas por tais personagens e as categoriza em termos olfativos, visuais e auditivos. São todos possuídos, quer em seus sonhos ou mesmo acordados, por criaturas monstruosas sem que disso se deem conta 
a princípio, mas tal possessão os levará à aniquilação final, fechando o ciclo das narrativas.

No segundo capítulo do livro, "Os Malefícios do Passado", Furtado localiza em detalhes a origem de tal avidez ou dos fenômenos que a despertam, tais como tesouros escondidos, maldições perdidas, eventos desconhecidos provenientes de um passado mítico que retornam para causar a destruição de quem as persegue ou liberta. Como afirma Furtado,

$\mathrm{Na}$ maioria das narrativas fantásticas, a intriga mantém relações de índole variada com o passado distante, secular, em especial, por estar nele situada a origem da manifestação metaempírica. Enquanto o fantástico romântico não recua no tempo para além da Idade Média, o fantástico dos fins do século XIX e das primeiras décadas do século $X X$ procura o passado mítico, a noite dos tempos. (p.81)

Segundo Furtado, "Lovecraft [...] aponta, quase sempre, a existência dum passado incomensurável, pré-humano, onde teriam tido origem as forças abomináveis desencadeadas no presente" (p.82). O contato com tais forças seria gerado pela avidez intelectual de quem resolvesse investigá-las, como acontece em vários dos contos elencados por Furtado. Isso os leva, muitas vezes, aos recônditos da Terra, rumo a territórios inóspitos e inexplorados, porta de entrada para esse universo mítico e acesso liberador de criaturas monstruosas arquetípicas. Assim é "Nas montanhas da loucura" e "A cidade sem nome", por exemplo.

No capítulo 3, "O verossímil: fatos e documentos", como o título já antecipa, Furtado demonstra a necessidade da construção de 
verossimilhança graças ao recurso a provas documentais, históricas e testemunhais para que o efeito de fantástico seja criado. Além disso, a avidez intelectual é nutrida por tais provas e por elas levada rumo ao desconhecido, à possessão e destruição. O faro investigativo das personagens-pesquisadoras as leva à busca por provas, manuscritos, testamentos, toda sorte de elementos que comprovem a existência de criaturas míticas, territórios perdidos, fenômenos inexplorados e inexplicáveis sem eles.

No capítulo 4, paralelo a este último e intitulado "O verossímil: recursos e insuficiências", Furtado discute como, para além de documentos históricos e provas concretas, o fantástico lovecraftiano se nutre de uma verossimilhança construída a partir de "mitos e outros aspectos encenados nos textos [que] atuam simultaneamente como sujeitos e objetos do verossímil" e que, segundo Furtado, "é o que se pode denominar referências intertextuais" (p.112). Trata-se de uma densa rede de citações e alusões a "situações, personagens, locais ou objetos já surgidos noutras [narrativas], as quais se tornam, desse modo, elementos confirmativos, funcionando como um sistema de testemunhos em circuito fechado" (p.112). Cria-se assim uma "rede de confiabilidade", o efeito de verossimilhança autorreferenciada e falsa, posto que ficcional, mas crível. Além de citações de suas próprias obras, Lovecraft também recorre a textos de autores como Charles Lamb e Edgar Allan Poe.

No capítulo 5, "Dizer o sobrenatural", Furtado aponta como Lovecraft elabora a tênue tessitura entre realidade e sobrenatural, concretude e universo metaempírico, de forma a manter a característica fundamental do fantástico, a ambiguidade. Analisando alguns contos lovecraftianos, mostra como a construção de 
personagens, tempo e espaço e a presença de imagens hiperbólicas e grotescas passa por tal tessitura e a constitui, elaborando o equilíbrio entre crer e duvidar.

O capítulo 6, "O monstro e os outros", é o mais curto do livro, embora nele Furtado aprofunde a taxonomia das personagens e situações dos contos lovecraftianos através da elaboração de modelos actanciais em quadros esquemáticos. Nesses modelos, Furtado trabalha com as seguintes categorias: sujeito, objeto, destinador, adjuvante, destinatário e oponente (p.150-151). Assim, busca classificar e definir o monstro, seu oponente-exterminador e as demais personagens em contos como "The Case of Charles Dexter Ward", "The Whisperer in Darkness" e "The Dunwich Horror $^{\prime 1}$, mostrando seu papel dentro do gênero fantástico e, ao mesmo tempo, deixando claro quando não pertencem a tal gênero e se aproximam mais do maravilhoso ou do estranho.

No capítulo 7, "Os Dois Lados da Narração”, Furtado retoma o que discute em seu livro de 1980 sobre a centralidade do narrador como criador do narratário e dos efeitos de ambiguidade nos contos fantásticos. Discorrendo longamente sobre tais categorias, Furtado mostra como Lovecraft se utiliza em grande parte (em $80 \%$ dos contos, segundo o crítico português) de um narrador em primeira pessoa. Desses, em $90 \%$ dos casos, conforme porcentagem igualmente calculada por Furtado, temos a figura de um narrador homodiegético, ou seja, "coincidente[s] com personagens" (p.154) e, em grande parte, autodiegéticos, ou quem "desempenha a função de destinatário-vítima" (p.154). Assim, o narrador auxilia a criar o efeito de fantástico, de dubiedade do qual se nutrem narrativas do 1 Títulos mantidos em inglês no livro, já que não foram traduzidos para o português. 
gênero. A pouca ou nenhuma distância com relação ao sujeito da enunciação, segundo Furtado, garante tal efeito.

No capítulo 8, "As Duplicidades do Espaço", novamente a taxonomia entra em ação. Desta vez, Furtado categoriza o espaço de forma esquemática, dividindo-o em planos entre realista e alucinado. O espaço realista, por sua vez, é dividido entre "geográfico"2 e imaginário. Já o alucinado recebe mais subdivisões: "duplo", não euclidiano e onírico. O espaço alucinado duplo é subdividido entre "do espaço geográfico" e "do espaço imaginário"; já o espaço alucinado onírico é dividido entre figurativo e não figurativo (p.167). Cada um desses planos é definido e exemplificado no texto, mostrando como ajudam a criar efeitos de ambiguidade de forma complexa no universo lovecraftiano, uma arquitetura bem elaborada. No entanto, como lembra Furtado, "o espaço encenado na ficção lovecraftiana resulta do emprego, consideravelmente elaborado, de processos bastante vulgares no fantástico" (p.167). Ou seja, no entender de Furtado, trata-se de um recurso bastante usual ao gênero e, portanto, não exclusivo de Lovecraft.

O capítulo 9, "As Armadilhas do conhecimento", começa com considerações teóricas acerca da análise temática de uma obra literária. Em seguida, passa a discorrer acerca de temas na obra de Lovecraft em interlocução com o que Furtado chama de "simbologia do conhecimento" (p.182). Diz-nos o autor:

Os temas recorrentes nas narrativas de Lovecraft evidenciam diversos elementos que formam uma simbologia do conhecimento: nas personagens (cientistas, professores universitários, artistas e outros intelectuais); no espaço (bibliotecas, 2 As aspas aqui são oriundas do original, não se tratando de uma citação do texto do Furtado. 
laboratórios, universidades); nos objetos que o povoam (livros e documentos de toda a ordem); na ação, tantas vezes centrada na busca do saber; no próprio ato narrativo produtor, muitas vezes, entrecortado por reflexões sobre a validade do processo cognitivo ou tiradas sobre o universo e os mistérios. Seus textos privilegiam, claramente, 0 predomínio - tanto quantitativo quanto funcional dos temas que supõem uma relação contemplativa homem-universo. (p.182-183)

Esse universo de busca do conhecimento, muitas vezes ávida e desenfreada, culmina, como anuncia Furtado já no primeiro capítulo do livro, na possessão e destruição de seus actantes. Afinal, acaba por liberar a monstruosidade, por "acordar" a criatura adormecida, por revelar a incapacidade de controlar o que se busca compreender:

O conhecimento científico faz surgir interrogações ou horrores que quase sempre superam, em número e magnitude, os problemas que consegue resolver. Por outro lado, a ciência tem tão só a medida do homem, hipervalorizando tudo o que a ele respeita e deixando escapar, quase por completo, a verdadeira dimensão do cosmos. (p.190)

É a essa conclusão a que chega Furtado nesse capítulo, mostrando como tal possessão e destruição acontecem em alguns dos contos, como a ciência é, no fim das contas, falha e cheia de armadilhas.

O capítulo 10, "Um Darwinismo Cósmico", serve de conclusão ao livro, mostrando como o desconhecido sobrepuja o cientista, o ser humano ávido de conhecimento, mas que não possui a força necessária para tudo dominar e conhecer. Em espécie de Darwinismo 
às avessas (em vez de evolução científica, com vitória do mais forte, do mais desenvolvido - o que seria de se esperar do homem com apoio da ciência - temos uma involução, um regresso histórico, com destruição inexorável que a tudo e todos atinge, inclusive o monstro e seu oponente-antagonista, o cientista. No final, a vitória, caso possa-se usar esse termo, é do Cosmos, universo que não se pode conhecer na íntegra.

O fantástico: procedimentos de construção narrativa em H.P. Lovecraft é, portanto, obra imprescindível para todos os que estudam o fantástico, obra de fôlego e com leitura vertical sobre a obra de Lovecraft. Vale muito a pena para quem quer entender como funciona uma análise estrutural da narrativa (ecoando Barthes), bem como para os estudiosos de Lovecraft, autor até então pouquíssimo estudado no Brasil. O livro lança, assim, luz intensa à fortuna crítica do autor norte-americano, não só no Brasil, mas em todo o mundo lusófono. Foi preciso esperar longos trinta e oito anos para que viesse a público e, desde já, entrasse no panteão de estudos teórico-críticos do fantástico em língua portuguesa. 